\title{
Pensar a internacionalização
}

Apresentamos aos nossos leitores o volume 25 (1) da Revista de Terapia Ocupacional da USP, nele estão reunidas contribuições de pesquisadores de diversas instituições de ensino: Centro Universitário Claretiano (CEUCLAR); Universidade Federal do Triângulo Mineiro (UFTM); Universidade de Brasília (UNB): Universidade Federal de Santa Catarina (UFSC); Universidade do Estado de Santa Catarina, (UDESC); Universidade Federal de São Carlos (UFSCAR); Universidade de São Paulo (USP); Universidade Federal de São Paulo (UNIFESP); Universidade Federal do Triângulo Mineiro (UFTM); Universidade de Campinas (UNICAMP) e Universidade Federal do Paraná (UFPR). É importante perceber que nossa Revista tem se tornado um veículo para pesquisadores de todo o Brasil e que a política de acesso aberto tem possibilitado novos diálogos e intercâmbios antes impossíveis.

A Terapia Ocupacional brasileira tem ancorado parte substantiva de sua produção científica nas experiências e inovações trazidas, especialmente pelas novas formas de pensar e agir em saúde propiciadas no contexto da politica pública de saúde e, em menor grau, nas demais políticas públicas.

Essa característica confere um caráter singular á Terapia Ocupacional nacional que merece divulgação e internacionalização. Dessa forma que é preciso refletir sobre como tal produção pode ser compartilhada.

Nessa direção a Revista pretende se lançar ao desafio gradual da publicação bilíngue (português-Inglês) de artigos originais, que será orientado por uma política editorial e também partilhado, de acordo com o interesse dos autores.

Acreditamos ser essa uma forma de ampliar os horizontes da Terapia Ocupacional brasileira em direção á divulgação e circulação da pesquisa nacional na área. Este tipo de iniciativa, que tem mostrado resultados significativos em outras áreas da publicação em saúde, poderá também contribuir para o processo da área.

Ao longo do próximo semestre passaremos a divulgar esse projeto.

Contamos com a sua colaboração!

Aceite o convite!

Elisabete Ferreira Mângia

Selma Lancman

Editoras da Revista de Terapia Ocupacional da USP 